\section{ENHANCING TUBERCULOSIS DIAGNOSIS BY POLYMERASE CHAIN REACTION: AN EXPERIENCE AT A TERTIARY HOSPITAL}

Clin Biomed Res. 2016;36(1):18-22

1 Laboratório de Biologia Molecular, Serviço de Patologia Clínica, Hospital de Clínicas de Porto Alegre (HCPA). Porto Alegre, RS, Brazil.

2 Unidade de Microbiologia, Serviço de Patologia Clínica, Hospital de Clínicas de Porto Alegre (HCPA). Porto Alegre, RS, Brazil.

3 Laboratório de Pesquisa em Resistência Bacteriana (LABRESIS), Centro de Pesquisa Experimental, Hospital de Clínicas de Porto Alegre (HCPA). Porto Alegre, RS, Brazil.

Corresponding author: Fernanda de-Paris fparis@hcpa.edu.br Laboratório de Biologia Molecular, Serviço de Patologia Clínica, Hospital de Clínicas de Porto Alegre

Rua Ramiro Barcelos, 2350

90035-903, Porto Alegre, RS, Brazil.

\begin{abstract}
Introduction: Tuberculosis (TB) persists as a severe global public health issue. The aim of the present study was to evaluate the performance of an in-house TB $\mathrm{PCR}$ (polymerase chain reaction) in sputum.
\end{abstract}

Methods: DNA from sputum specimens were submitted to a nested-PCR protocol for the IS6110 region detection. PCR results were compared to those of the traditional methods for TB diagnosis, i.e., acid-fast bacilli (AFB) smear microscopy and culture. We analyzed sputum samples obtained from 133 patients.

Results: A total of $48(36 \%)$ cultures yielded indeterminate results due to contamination. This high contamination rate may be explained by the fact that samples from fibrocystic patients were included in this study. Additionally, other five samples were positive for nontuberculous mycobacteria (NTM). Therefore, it was possible to compare 80 patients for M. tuberculosis detection. We found 14 positive samples: five presented positive results in the three methods $(5 / 14 ; 35.7 \%)$, two were positive in culture and PCR $(2 / 14$; $14.3 \%)$, one was positive in AFB and PCR $(1 / 14 ; 7.1 \%)$, five were positive only in PCR $(5 / 14 ; 35.7 \%)$ and 1 was positive only in culture $(1 / 14 ; 7.1 \%)$. Thus, positivity rates for each technique were: $7.5 \%$ for AFB (6/80), $10 \%$ for culture (8/80) and $16.25 \%$ for PCR (13/80). Among the 48 patients who had indeterminate results in sputum culture, two samples were positive in PCR.

Conclusion: Considering the limitations of the traditional methods, the use of PCR as a molecular technique could be advantageous for TB diagnosis.

Keywords: Mycobacterium sp.; pulmonary tuberculosis; nucleic acid amplification tests; polymerase chain reaction

Tuberculosis (TB) persists as a severe global public health threat ${ }^{1-3}$ with more than 9 million new cases worldwide every year ${ }^{4}$. Inadequate case detection and low cure rates have been identified as reasons for the mounting global TB burden ${ }^{5}$. Consequently, the development of methods that aid in prompt and correct identification of infected patients is very important. This will contribute to proper treatment adherence, which is the main strategy to reduce TB epidemics ${ }^{6}$.

Concerning diagnosis, acid-fast bacilli (AFB) smear microscopy and sputum culture have been advocated as two useful laboratory tools for diagnosis of pulmonary TB. However, these conventional tests may present limitations. AFB smear microscopy is a rapid and inexpensive test, although with limited accuracy due to its poor sensitivity (45\%-80\% in culture-confirmed pulmonary TB cases) $)^{7,8}$, whereas TB culture requires long periods of incubation (2-8 weeks).

In this scenario, nucleic acid amplification (NAA) tests have emerged as promising alternatives for TB diagnosis ${ }^{9}$. Polymerase chain reaction (PCR) is the best known and most widely used NAA test. NAA tests are categorized as commercial (kit-based) or in-house ("home-brew"). In-house tests are those assays where the investigators design their own protocols. In-house tests 
are commonly used in developing countries where commercial kits are hardly affordable ${ }^{9}$. Guidelines recommend the use of NAA tests on at least one respiratory specimen from patients with negative AFB smear in whom a diagnosis of TB is being considered $^{1,7,10,11}$. The aim of the present study was to evaluate the performance of an in-house TB PCR, in comparison to AFB smear microscopy and TB culture in sputum from patients with suspected TB.

\section{METHODS}

\section{Patients' Samples}

Consecutive patients with suspected diagnosis of TB attending at Hospital de Clínicas de Porto Alegre (a tertiary care hospital in southern Brazil) from October 2007 to March 2008, for whom a sputum sample for TB culture was ordered, were considered for inclusion in the study. There was no exclusion criterion. Samples in this study were taken as part of standard care. Ethical approval was granted by the Ethical Committee of Hospital de Clínicas de Porto Alegre (no. 07-363).

\section{Microbiological Methods}

Microscopic examination of sputum smears for AFB using the Ziehl-Neelsen method was performed in all samples. For culture, the samples were digested and decontaminated using $2 \% \mathrm{NaOH}$ with $\mathrm{N}$-acetylcysteine. Afterwards, the samples were subcultured in Löwenstein-Jensen media. All cultures were incubated at $37{ }^{\circ} \mathrm{C}$ for 8 weeks and checked weekly. Any colony consistent with Mycobacterium $s p$. during this period was submitted to AFB staining to confirm the presence of bacterium ${ }^{12}$.

All positive cultures were subcultured in liquid broth $\mathrm{BBL}{ }^{\circledR}$ MGIT and incubated in the automated system Mycobacteria Growth Indicator Tube (MGIT) $960^{\circledR}$ System (BBL, Becton Dickinson Microbiology Systems, Hunt Valley). The p-nitrobenzoic acid (PNB) test was performed to differentiate the Mycobacterium tuberculosis (MTB) complex from nontuberculous mycobacteria (NTM).

\section{Polymerase Chain Reaction (PCR)}

A volume of $1 \mathrm{~mL}$ from all decontaminated samples was stored at $-20{ }^{\circ} \mathrm{C}$ to further perform the PCR technique. The samples were thawed and treated with proteinase K. The Qiagen $\mathrm{kit}^{\circledR}$ was used, according to manufacturer's instructions for DNA extraction. The PCR technique was performed in duplicate for each sample, using a nested protocol with primers for the IS6110 insertion sequence. The sequence of primers used was described by Sechi et al. ${ }^{13}$ for the MTB complex (table 1).

An aqueous mixture containing $1.25 \mathrm{U}$ of Taq polymerase DNA enzyme (Super-Therm, JMR Holdings, London, UK), buffer, $1.5 \mathrm{mM}$ of $\mathrm{MgCl}_{2}, 250 \mu \mathrm{M}$ of dNTP (Abgne ${ }^{\circledR}$, Epson, UK), and $500 \mathrm{nM}$ of external primers was used in this reaction. The amplification was conducted in a Techne ${ }^{\circledR}$ thermocycler (Techne ${ }^{\circledR}$, New Jersey, USA). The reaction consisted of initial denaturation at $94{ }^{\circ} \mathrm{C}$ for 1 minute and 40 seconds, followed by 33 cycles of denaturation at $94{ }^{\circ} \mathrm{C}$ for 30 seconds, annealing at $55^{\circ} \mathrm{C}$ for 30 seconds, and polymerization at $72^{\circ} \mathrm{C}$ for 30 seconds. In the second amplification reaction, $2 \mu \mathrm{L}$ of internal primers were added to the product of the first reaction in a mixture with the same proportion of the reagents above. The reaction consisted of initial denaturation at $94{ }^{\circ} \mathrm{C}$ for 45 seconds followed by 33 cycles of denaturation at $94{ }^{\circ} \mathrm{C}$ for 20 seconds, annealing at $55{ }^{\circ} \mathrm{C}$ for 20 seconds, and polymerization at $72{ }^{\circ} \mathrm{C}$ for 30 seconds.

The final products from the second reaction of nested PCR were run on $2 \%$ agarose gel stained with ethidium bromide. All samples that showed a DNA band of 170 base pairs were considered positive.

For patients with more than one sputum sample collected for AFB or TB culture, only the first sample was processed for TB PCR and included in our analysis.

\section{RESULTS}

In the period described above, 201 consecutive samples were processed. These samples were obtained from 133 patients ( 77 males and 56 females) with a mean age of 44.9 years. A total of $30.8 \%(41 / 133)$ samples were obtained from cystic fibrosis (CF) patients and $14.3 \%$ (19/133) were from HIV positive patients. In addition, there were $21.8 \%(29 / 133)$ of patients with reported previously TB (table 2 ).

Culture for diagnosis of tuberculosis was positive in $13(9.8 \%)$ patients. Eight isolates from these patients were identified as MTB and five were identified as NTM in the PNB test. However, 48 (36\%) cultures yielded indeterminate results due to contamination (growth

Table 1: Sequence of primers used in polymerase chain reaction for tuberculosis.

\begin{tabular}{cccc}
\hline \multirow{2}{*}{ External primers } & TB290 & 5'GGC GGG ACA ACG CCG AAT TGC GAA & \multirow{2}{*}{ 600pb } \\
& TB856 & 5'CGA GCG TAG GCG TCG GTG ACA AAG & \multirow{2}{*}{ 170pb } \\
\hline \multirow{2}{*}{ Internal primers } & TB500 & 5'TAC TAC GAC CAG ATC & 5'TTG GTG ATC AGC CGT \\
\hline
\end{tabular}


of yeasts or other bacteria). Among contaminated cultures, $23(47.9 \%)$ were obtained from CF patients.

AFB was detected in only eight samples $(6 \%)$; five were positive for MTB (culture and PCR results) but three presented either negative or indeterminate culture results. Among these latter three samples, two presented positive PCR for MTB.

According to the PCR assay, a total of $15(11.3 \%)$ patients presented positive results for MTB complex. Seven were also positive for MTB in culture and eight presented either negative culture (six samples) or contaminated (two samples). Noteworthy, all five NTM identified by culture proved to be negative for MTB complex by PCR (table 3 ).

It was possible to compare the AFB and PCR techniques with culture assays with regard to MTB detection in 80 patients (excluding 48 cultures with indeterminate results and five cultures positive for NTM). The following positivity rates were observed for each technique: $7.5 \%$ for AFB smear (6/80), $10 \%$ for culture (8/80) and $16.25 \%$ for PCR (13/80). Among the 14 positive samples, five presented positive results in the three methods $(5 / 14 ; 35.7 \%)$, two were positive in culture and PCR $(2 / 14 ; 14.3 \%)$, one was positive in AFB smear and PCR $(1 / 14 ; 7.1 \%)$, five were positive only in $\mathrm{PCR}(5 / 14 ; 35.7 \%)$, and one was positive only in culture $(1 / 14 ; 7.1 \%)$ (table 3 ).

The sensitivity of PCR was $87.5 \%$, specificity was $91.7 \%$, positive predictive value (PPV) was $53.8 \%$, and negative predictive value (NPV) was $98.5 \%$.

Additionally, we could observe that, in the 48 patients whose culture was lost due to contamination, one sample was positive in AFB smear and PCR, one sample was positive only in AFB smear, and 1 sample was positive only in PCR (table 3).

\section{DISCUSSION}

Conventional tests for laboratory confirmation of TB include AFB smear microscopy and culture ${ }^{14}$. In the present study, a NAA test (in-house nested-PCR protocol), was evaluated as an adjunct test in the diagnostic strategy for TB detection in sputum samples. With the PCR technique (considering MTB detection) the positivity rate obtained was $16.25 \%(13 / 80)$ and cultural method the positivity rate was $7.5 \%(6 / 80)$ and $10 \%(8 / 80)$, respectively. Other important finding was that among positive samples for PCR, 9 were positive for one of the traditional methodologies.

Only one sample positive for TB in the culture method had negative PCR. This fact can be associated

Table 2: Characteristics of patients participating in this study.

\begin{tabular}{cccc}
\hline HIV status & Cystic fibrosis (CF) & $\begin{array}{c}\text { Previous diagnosis of } \\
\text { Mycobacterium }\end{array}$ & Number of patients \\
\hline- & - & - & 56 \\
- & + & - & 34 \\
- & + & + & $7(3$ TB +4 NTM) \\
+ & - & - & 5 (only TB) \\
+ & - & + & 17 (only TB) \\
- & - & & Total = 133
\end{tabular}

Table 3: Results from 133 patients (culture, AFB and PCR).

\begin{tabular}{|c|c|c|c|c|}
\hline \multirow{2}{*}{$\begin{array}{l}\text { Patients } \\
(n=133)\end{array}$} & \multicolumn{2}{|c|}{ Culture } & \multirow{2}{*}{ AFB } & \multirow{2}{*}{ PCR } \\
\hline & M. tuberculosis & NTM & & \\
\hline 66 & - & - & - & - \\
\hline 45 & NR & NR & - & - \\
\hline 5 & - & - & - & + \\
\hline 5 & - & + & - & - \\
\hline 5 & + & - & + & + \\
\hline 2 & + & - & - & + \\
\hline 1 & + & - & - & - \\
\hline 1 & - & - & + & + \\
\hline 1 & NR & NR & - & + \\
\hline 1 & NR & NR & + & + \\
\hline 1 & NR & NR & + & - \\
\hline
\end{tabular}

$\mathrm{NR}$ = no result due contamination; "-" = negative; "+" = positive and NTM = nontuberculous mycobacteria. 
with the presence of inhibiting substances of DNA polymerase enzyme in the sputum ${ }^{11}$. In contrast, two samples were positive in AFB and PCR but negative or indeterminate in culture. Therefore, the culture method may produce false-negative results, although it is traditionally considered as gold standard. The culture technique may be influenced by a variety of conditions that do not influence the PCR assay, which may explain, at least partially, the finding of higher positivity rates in the PCR technique. In this study, among the six patients positive for MTB only in the PCR technique, there were two samples obtained from patients previously diagnosed with TB.

Considering the 80 patients tested by the three methods in our study, the sensitivity and specificity rates of PCR compared to culture was $87.5 \%$ and $91.7 \%$, respectively. A study conducted by Rozales et al. showed that real-time PCR ( $\mathrm{PPCR}$ ) and conventional in-house PCR (nPCR) also presented high sensitivity and specificity (qPCR $97.6 \%$ and $91.5 \%$, nPCR $85.7 \%$ and $92.7 \%$, respectively) compared to culture ${ }^{3}$. Another study in that UK that used commercial NAA tests, found a sensitivity rate of $87 \%$ and a specificity rate of $75 \%{ }^{1}$. We believe that our nPCR technique has comparable performance to commercial tests that have their use recommended only in smear-positive samples.

In this study, we could observe an important limitation of the culture method: contamination. A considerable number of culture samples yielded indeterminate results $(48 / 133,36 \%)$. Among the 48 patients whose samples were contaminated in the culture method, there were two positive samples were in PCR.

\section{CONCLUSION}

The current study presents some limitations, such as the lack of sequencing of PCR positive samples, in order to confirm the good performance of PCR and its positive results, as well as the use of internal control to validate negative samples. Respecting the limitations of this study, the results obtained are promising with regard to the use of PCR in TB diagnosis.

Furthermore, considering the limitations of the gold standard method discussed in this study (contaminated cultures, unviable growth due to the decontamination method, etc.) and the fact that culture is considered a cumbersome and time-consuming technique ${ }^{14,15}$, the use of PCR could be advantageous for TB diagnosis. PCR could reduce diagnosis time, which will impact directly on the reduction of the transmission chain of this important disease ${ }^{10}$.

In summary, the addition of PCR test can contribute greatly to TB diagnosis, especially in samples whose culture was lost due to contamination.

\section{Acknowledgements}

We are grateful for the financial support of Fundo de Incentivo à Pesquisa e Eventos, Hospital de Clinicas de Porto Alegre (FIPE/HCPA), Fundação de Amparo à Pesquisa do Estado do Rio Grande do Sul (FAPERGS) and Conselho Nacional de Desenvolvimento Científico e Tecnológico (CNPq).

\section{REFERENCES}

1. Taegtmeyer M, Beeching NJ, Scott J, Seddon K, Jamieson S, Squire $\mathrm{SB}$, et al. The clinical impact of nucleic acid amplification tests on the diagnosis and management of tuberculosis in a British hospital. Thorax. 2008;63(4):317-21. http:// dx.doi.org/10.1136/thx.2007.083816. PMid:18024540.

2. Centers for Disease Control and Prevention - CDC. Trends in tuberculosis: United States, 2008. MMWR Morb Mortal Wkly Rep. 2009;58(10):249-53. PMid:19300406.

3. Rozales FP, Machado AB, De Paris F, Zavascki AP, Barth AL. PCR to detect Mycobacterium tuberculosis in respiratory tract samples: evaluation of clinical data. Epidemiol Infect. 2014;142(7):1517-23. http://dx.doi. org/10.1017/S0950268813002598. PMid:24107314.
4. Lönnroth K, Castro KG, Chakaya JM, Chauhan LS, Floyd K, Glaziou $\mathrm{P}$, et al. Tuberculosis control and elimination 2010-50: cure, care, and social development. Lancet. 2010;375(9728):1814-29. http://dx.doi. org/10.1016/S0140-6736(10)60483-7. PMid:20488524.

5. Siddiqi K, Lambert ML, Walley J. Clinical diagnosis of smear-negative pulmonary tuberculosis in low-income countries: the current evidence. Lancet Infect Dis. 2003;3(5):288-96. http://dx.doi.org/10.1016/S14733099(03)00609-1. PMid:12726978.

6. Bark CM, Okwera A, Joloba ML, Thiel BA, Nakibali JG, Debanne SM, et al. Time to detection of Mycobacterium tuberculosis as an alternative to quantitative cultures. Tuberculosis. 2011;91(3):257-9. http://dx.doi. org/10.1016/j.tube.2011.01.004. PMid:21353641.

7. Centers for Disease Control and Prevention - CDC. Updated guidelines for the use of nucleic acid amplification tests in the diagnosis of tuberculosis. MMWR Morb Mortal Wkly Rep. 2009;58(1):7-10. PMid:19145221.

8. Guerra RL, Hooper NM, Baker JF, Alborz R, Armstrong DT, Maltas $G$, et al. Use of the amplified mycobacterium tuberculosis direct test in a public health laboratory: test performance and impact on clinical care. Chest. 2007;132(3):94651. http://dx.doi.org/10.1378/ chest.06-2959. PMid:17573496.

9. Flores LL, Pai M, Colford JM JR, Riley LW. In-house nucleic acid 
amplification tests for the detection of Mycobacterium tuberculosis in sputum specimens: metaanalysis and meta-regression. BMC Microbiol. 2005;5(1):55. http:// dx.doi.org/10.1186/1471-2180-5-55. PMid:16202138.

10. Kobayashi M, Ray SM, Hanfelt J, Wang YF. Diagnosis of tuberculosis by using a nucleic acid amplification test in an urban population with high HIV prevalence in the United States. PLoS One. 2014;9(10):e107552. http://dx.doi.org/10.1371/journal. pone.0107552. PMid:25340424.

11. Conde MB, Melo FA, Marques AM, Cardoso NC, Pinheiro VG,
Dalcin PT, et al. III Brazilian Thoracic Association Guidelines on tuberculosis. J Bras Pneumol. 2009;35(10):1018-48. PMid:19918635.

12. Brasil. Ministério da Saúde. Manual nacional de vigilância laboratorial da tuberculose e outras micobactérias. Brasília; 2008.

13. Sechi LA, Pinna MP, Sanna A, Pirina P, Ginesu F, Saba F, et al. Detection of Mycobacterium tuberculosis by PCR analysis of urine and other clinical samples from AIDS and non-HIV-infected patients. Mol Cell Probes. 1997;11(4):281-5. http:// dx.doi.org/10.1006/mcpr.1997.0119. PMid:9281414.
14. Moore DF, Guzman JA, Mikhail LT Reduction in turnaround time for laboratory diagnosis of pulmonary tuberculosis by routine use of a nucleic acid amplification test. Diagn Microbiol Infect Dis. 2005;52(3):24754. http://dx.doi.org/10.1016/j. diagmicrobio.2005.02.014. PMid:15893903.

15. Adelman MW, Kurbatova E, Wang YF, Leonard MK, White N, McFarland DA, et al. Cost analysis of a nucleic acid amplification test in the diagnosis of pulmonary tuberculosis at an urban hospital with a high prevalence of TB/ HIV. PLoS One. 2014;9(7):e100649. http://dx.doi.org/10.1371/journal. pone.0100649. PMid:25014783.

Received: Dez 31, 2015 Accepted: Mar 24, 2016 